\title{
Diurnal variability of inner-shelf circulation in the lee of a cape under upwelling conditions
}

\author{
L. Lamas ${ }^{\mathrm{a}, \mathrm{b}, *}$, A. Peliz ${ }^{\mathrm{b}}$, J. Dias ${ }^{\mathrm{a}}$, P.B. Oliveira ${ }^{\mathrm{c}}$, M.M. Angélico ${ }^{\mathrm{c}}$, J.J. Castro $^{\mathrm{d}}$, J.N. Fernandes ${ }^{\mathrm{d}}$, \\ A. Trindade ${ }^{\mathrm{e}}, \mathrm{T}$. Cruz $^{\mathrm{d}}$ \\ a MARE - Marine and Environmental Sciences Centre, Faculdade de Ciências da Universidade de Lisboa, Campo Grande 1749-016, Lisboa, Portugal \\ b Instituto Dom Luiz, Faculdade de Ciências da Universidade de Lisboa, Campo Grande 1749-016, Lisboa, Portugal \\ ${ }^{c}$ Instituto Português do Mar e Atmosfera, 1449-006 Lisboa, Portugal \\ d MARE - Marine and Environmental Sciences Centre, Laboratório de Ciências do Mar, Universidade de Évora, 7520-903 Sines, Portugal \\ e Institut de Ciències del Mar, Departament Oceanografia Física i Tecnològica, 37-4908003 Barcelona, Spain
}

\section{A R T I C L E I N F O}

\section{Keywords:}

Coastal oceanography

Wind-driven circulation

Upwelling

Diurnal variability

Topography

Inner-shelf circulation

\begin{abstract}
A B S T R A C T
The nearshore circulation in the lee of a cape under upwelling conditions was studied using in-situ data from 3 consecutive summers (2006-2008). Focus was given to a period between 20 July and 04 August 2006 to study the diurnal variability of the cross-shelf circulation. This period was chosen because it had a steady upwellingfavourable wind condition modulated by a diurnal cycle much similar to sea breeze.

The daily variability of the observed cross-shelf circulation consisted of three distinct periods: a morning period with a 3-layer vertical structure with onshore velocities at mid-depth, a mid-day period where the flow is reversed and has a 2-layer structure with onshore velocities at the surface and offshore flow below, and, lastly, in the evening, a 2-layer period with intensified offshore velocities at the surface and onshore flow at the bottom. The observed cross-shelf circulation showed a peculiar vertical shape and diurnal variability different from several other systems described in literature. We hypothesize that the flow reversal of the cross-shelf circulation results as a response to the rapid change of the wind magnitude and direction at mid-day with the presence of the cape north of the mooring site influencing this response.

A numerical modelling experiment exclusively forced by winds simulated successfully most of the circulation at the ADCP site, especially the mid-day reversal and the evening's upwelling-type structure. This supports the hypothesis that the cross-shelf circulation at diurnal timescales is mostly wind-driven. By analysing the 3D circulation in the vicinity of Cape Sines we came to the conclusion that the diurnal variability of the wind and the flow interaction with topography are responsible for the circulation variability at the ADCP site, though only a small region in the south of the cape showed a similar diurnal variability.

The fact that the wind diurnally undergoes relaxation and intensification strongly affects the circulation, promoting superficial onshore flows in the leeside of Cape Sines. Despite the small-scale nature of the observed cross-shelf circulation, onshore flows as the ones described in this study can be particularly helpful to understand the transport and settlement of larvae in this region and in other regions with similar topography and wind characteristics.
\end{abstract}

\section{Introduction}

The cross-shelf circulation over the nearshore region plays a key role on the distribution of plankton, nutrients, heat, salt and sediments, and has been the subject of many recent studies (Fewings et al., 2008; Lentz et al., 2008; Hendrickson and MacMahan, 2009; Marchesiello and Estrade, 2010; Ganju et al., 2011; Lentz and Fewings, 2012; Liu and Gan, 2014). Wind-driven upwelling and downwelling systems are particularly important because of the cross-shelf exchange that is forced in these wind conditions, which promotes transport of material across the shelf, especially over stratified shelves (Austin and Lentz, 2002). In the region onshore of the upwelling front, stratification is often weaker and the surface and bottom turbulent layers overlap, causing the reduction or shut-down of the cross-shelf transport (Estrade et al., 2008). This region is normally referred to as innershelf (Lentz, 2001; Austin and Lentz, 2002; Fewings et al., 2008). In

\footnotetext{
* Corresponding author at: MARE - Marine and Environmental Sciences Centre, Faculdade de Ciências da Universidade de Lisboa, Campo Grande 1749-016, Lisboa, Portugal.

E-mail addresses: lalamas@fc.ul.pt (L. Lamas), ajpeliz@fc.ul.pt (A. Peliz), jdias@fc.ul.pt (J. Dias), pboliveira@ipma.pt (P.B. Oliveira), mmangelico@ipma.pt (M.M. Angélico), jjc@uevora.pt (J.J. Castro), jfer@uevora.pt (J.N. Fernandes), atrindade@icm.csic.es (A. Trindade), tcruz@uevora.pt (T. Cruz).
} 
spite of weaker cross-shelf transport conditions, this shallow part of the shelf is an attractive habitat for many coastal species. For example, inter-tidal species, having their planktonic larval phase over the shelf, must cross the nearshore zone for settlement. Cross-shelf transport processes over the shelf are thus critical for the larvae supply to the shore, which then determines recruitment (Pineda et al., 2009). Understanding the physical processes behind the cross-shelf exchange over the inner-shelf is of particular interest for this type of studies.

The wind-driven shelf response over a straight coastline has been extensively studied. Upwelling-favourable winds drive cross-shelf exchange with an offshore flow at the surface boundary layer and a compensating onshore flow near the bottom. This occurs for depths typically greater than $50 \mathrm{~m}$, when the surface and bottom boundary layers are relatively thin when compared with total water depth (a region often called mid-shelf (Lentz and Fewings, 2012)). With strongly stratified waters, this region moves inshore as the turbulent layers thin due to stronger stratification, extending the cross-shelf circulation farther inshore when compared with unstratified conditions (Austin and Lentz, 2002; Horwitz and Lentz, 2014). Less is known for systems with complex topography variations. Divergences in the alongshelf and cross-shelf flows may occur with the presence of complex coastline topography and subtle bathymetric features, that can drive substantial cross-shelf exchange (Barth et al., 2000; Gan and Allen, 2002; Kirincich et al., 2005; Sanay et al., 2008; Ganju et al., 2011). As seen in several studies (Gan and Allen, 2002; Gutierrez et al., 2006; Kuebel Cervantes and Allen, 2006; Maza et al., 2006), strong alongshore pressure gradients can form in the presence of a cape, when the upwelling wind regime relaxes. These pressure gradients are accompanied by geostrophically balanced cross-shelf flows over the innershelf, resulting in the intensification of the upwelling in the lee of the cape. A cyclonic recirculation that may form in the presence of a cape, can also be relevant since it enhances the onshore transport in the leeside of the cape (Barth et al., 2000; Doglioli et al., 2004; Meunier et al., 2010; Liu and Gan, 2014).

here we conduct a study of the shelf circulation at a site with sharp along-shelf topography changes, and with a marked diurnal variability. the strong diurnal cycle of the wind motivated the focus on the daily variability of the circulation, since sea breeze events are found to be particularly important in promoting onshore transport across the inner-shelf, through its influence on both winds and waves (Woodson et al., 2007; Hendrickson and MacMahan, 2009; Lucas et al., 2013).

The study area lies within the meridional coast of Portugal around Cape Sines (Fig. 1). The shelf is relatively narrow (around $30 \mathrm{~km}$ ) with the shelf break at approximately $150 \mathrm{~m}$ depth. South of the Cape, the shore is mostly rocky and crucial for many inter-tidal species including barnacles (Cruz et al., 2005). The processes of barnacle recruitment at this site have been under investigation for many years now, in the frame of various projects (Cruz, 1999; Cruz et al., 2005; Jacinto and Cruz, 2008; Cruz et al., 2009; Trindade et al., 2016). We used Eulerian velocity measurements collected at $12-\mathrm{m}$ water depth in the lee of Cape Sines, over 3 consecutive summers (2006-2008). Summertime is the period when the larvae recruitment of several barnacle species is higher for the study region (Cruz, 1999; Cruz et al., 2005; Jacinto and Cruz, 2008), which can be particularly interesting since, during summer, the western Iberian coast is typically under upwelling-favourable winds (Relvas et al., 2007), which intensify the along-shelf currents and promote the shut-down of cross-shelf transport in the region inshore of the upwelling front (Estrade et al., 2008). However, in the presence of a cape, diurnal relaxation periods may induce retention-favourable conditions, which can be beneficial to larvae recruitment in the leeside of the cape (Roughan et al., 2005a, 2005b; Peliz et al., 2007; Woodson et al., 2007; Oliveira et al., 2009; Lucas et al., 2013).

We chose a period between 20 July and 04 August 2006 when the wind showed a steady upwelling-favourable condition modulated by a diurnal cycle of the wind. The use of a period with such stable wind forcing enabled us to minimize other forcing effects and to focus on the wind-driven part of the circulation. A numerical model simulation was also conducted to study the wind-driven circulation in the vicinity of Cape Sines during this period. This study adds new insights about the spatial patterns of the circulation at diurnal timescales in the leeside of Cape Sines and how transport across the shelf may be promoted.

\section{Data and methods}

\subsection{In-situ data}

Wind data for the summers of 2006, 2007 and 2008 were collected at the Meteorological station of the Port of Sines authority, at $37^{\circ} 57^{\prime}$ $25^{\prime \prime} \mathrm{N} ; 8^{\circ} 52^{\prime} 74^{\prime \prime} \mathrm{W}$ which is about $10 \mathrm{~km}$ North of the ADCP location (Fig. 1). Wave and tidal data for the same period were collected at $37^{\circ}$ $55^{\prime} 14^{\prime \prime} \mathrm{N} ; 8^{\circ} 55^{\prime} 47^{\prime \prime} \mathrm{W}$, and $37^{\circ} 56^{\prime} 89^{\prime \prime} \mathrm{N} ; 8^{\circ} 53^{\prime} 27^{\prime \prime} \mathrm{W}$ respectively (Fig. 1).

Four thermistors (Stowaway TidBit, Onset Computer Corp.) were deployed from July 19, 2006 to September 15, 2006 and from 1 to 14 of August 2007, on a mooring next to the ADCP location. Temperature was measured at 4 different depths: $1 \mathrm{~m}, 3 \mathrm{~m}$ and $5 \mathrm{~m}$ above the sea floor, and at the surface. A fifth thermistor was deployed in 2006 at $2 \mathrm{~m}$ from the surface.

Velocity profiles were measured with a bottom-mounted upward looking Acoustic Doppler Current Profiler (WorkHorse Sentinel $1200 \mathrm{kHz}$ ), with a bin size of $0.5 \mathrm{~m}$, and a ping frequency between 0.83 and $1.67 \mathrm{~Hz}$, deployed in approximately 12-m water depth at $37^{\circ}$ $53^{\prime} 11.52^{\prime \prime} \mathrm{N}, 8^{\circ} 48^{\prime} 15.42^{\prime \prime} \mathrm{W}$, and about $600 \mathrm{~m}$ offshore (Fig. 1). The data was collected in 2006, between July 19 and August 29; in 2007, between July 31 and August 14; and in 2008, between July 22 and September 9 (with a gap between August 05 and August 19). As bottom-mounted ADCPs do not sample the entire water column, the deepest bin corresponds to approximately $1.5 \mathrm{~m}$ above sea bed.

The upper bins of the ADCP correspond either to emersed or submersed depth cells depending on the height of the free surface, mainly due to tidal movements. Therefore it was first necessary to find the sea surface, and disregard all bins above that surface. To find the contaminated bins, and since the data was collected at a shallow location where the tidal amplitude ranges from $14 \%$ to $30 \%$ of the total depth, the 'tide-following method' was used (Kirincich et al., 2005). For each profile, the depth of maximum backscatter intensity was marked as the water surface and all bins above this surface were discarded, plus three bins immediately below it.

\subsection{Time-averaging and vertical coordinate transformation}

The fact that the sea surface undergoes significant changes in shallow waters rises the question of how to compute the daily time averages of data along the same depth. If a bottom or surface reference coordinate system is used (Kirincich et al., 2005; Fewings et al., 2008; Lentz et al., 2008), an average along the same z-level will include data that are at very different relative distances to the surface (especially in spring tides and shallow waters) and this will produce an aliased mean. To overcome this problem, a dynamical (tide-following) vertical coordinate $z^{\prime}=z / h$, where $\mathrm{h}$ is the total water column depth (changing with tides), was used. The total depth (or the sea surface height) was computed by adjusting the surface detected with the maximum of total backscatter intensity to the sea surface using the tidal height measured at the port of Sines (near the ADCP location, see Fig. 1). Each ADCP profile was then interpolated into this new coordinate system. Timeaveraging was then performed along each of the dynamical-surfaces, ensuring that the time-averaging of velocity values is done along levels that are at equal relative distances to the bottom and sea surface. The dynamical vertical coordinate conserves information of both bottom and surface bins and it was, therefore, the one chosen for this study.

The coordinate system was rotated based on the principal axis direction of the subtidal depth-averaged velocity. For most deploy- 

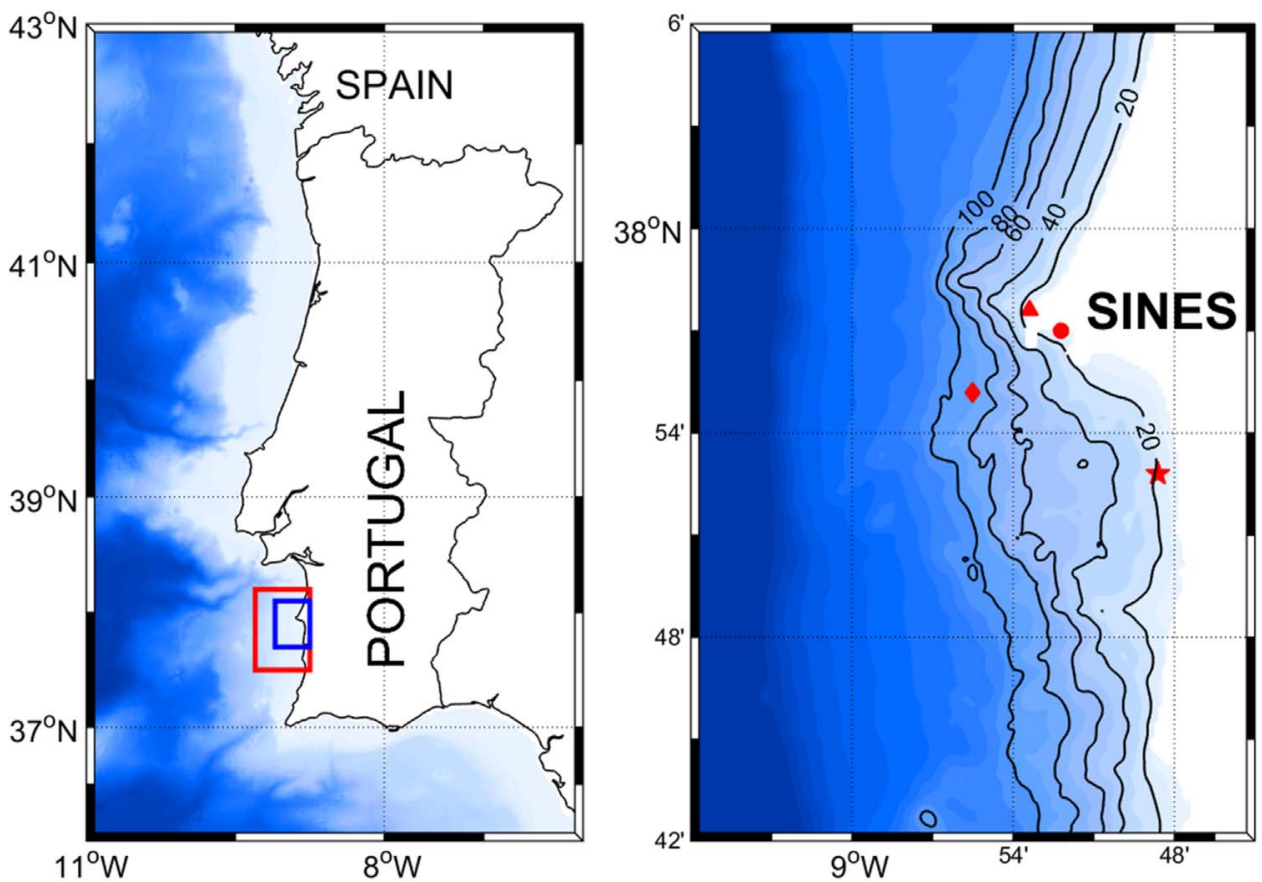

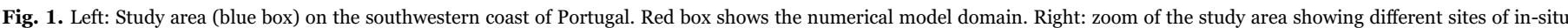

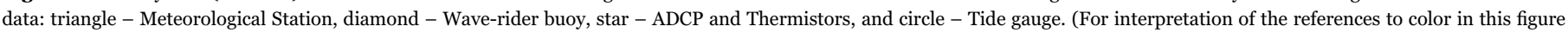
legend, the reader is referred to the web version of this article.)

ments, the major axis orientation was less than $2.4^{\circ}$ clockwise from north, and it was roughly aligned with local bathymetry and coastline. The coordinate axis was rotated according to this angle and the velocity profiles are now considered to be in cross-shelf $(x)$ and along-shelf $(y)$ directions, with $x$ negative offshore and $y$ positive along-shelf northwards.

All further analysis was performed with hourly averaged data.

\subsection{Model setup}

A numerical simulation was conducted using the Regional Ocean Modelling System (ROMS) (Shchepetkin and McWilliams, 2005; Haidvogel et al., 2008), a free-surface, terrain-following (sigma coordinate), primitive equation ocean model largely used for coastal applications.

The model configuration was developed to simulate the period between 20 July and 04 August 2006 in the region focused by this study (around Cape Sines, in the Southwestern coast of Portugal). The configuration consisted of a high resolution $(0.22 \mathrm{~km})$ grid in a $50 \times$ $80 \mathrm{~km}$ domain around Cape Sines (red square in Fig. 1). 32- $\sigma$ levels were used with enhanced vertical resolution at surface levels. Topography data compiled in Peliz et al. (2013) was used, with a low-level smoothing and a cut-off depth of $800 \mathrm{~m}$. Radiation conditions are used along the open boundaries for momentum and tracers, together with passive-active nudging open boundary forcing (Marchesiello et al., 2001). A sponge layer of $15 \mathrm{~km}$ is placed near the open boundaries to reduce reflections that tend to appear as a consequence of the reduced grid dimension.

The model initially assumes a flat ocean with a vertical density distribution typical of summer time. The same salinity and temperature conditions are preserved near the open boundaries using a relaxation time scale (Marchesiello et al., 2001). Homogeneous surface heat fluxes with a fixed diurnal variability are used to maintain the stratification (more details in Trindade et al. (2016)).

The model was forced with 15 days (between 20 July and 04 August 2006) of winds downscaled from Era-Interim data using the Weather Research and Forecast Model (Fig. 2), with $9 \mathrm{~km}$ resolution, to allow spatial inhomogeneity (Soares et al., 2012; Peliz et al., 2013). Since WRF model seems to systematically overestimate the winds when compared with the observed time series, the WRF wind magnitude was reduced by the time-mean wind magnitude difference between the data and model at the location of the meteorological station.

The focus of this study is to analyse the wind-driven circulation, and therefore tides were not included in the model forcing. A spin-up of 3 days was considered for the model to stabilize and the results from that period were disregarded. To avoid misinterpretations, the model description and analysis will be based on the zonal $(x)$ and meridional (y) oriented axis, with the consideration that away from the cape (including the ADCP site) it is coincident with the along- and crossshelf coordinate axis.

\section{Results}

\subsection{Observations}

\subsubsection{Winds}

Cross-shelf wind stress $\left(\tau_{s}{ }^{\mathcal{X}}\right)$ ranged, on average, between values of $-0.05 \mathrm{~Pa}$ and $0.05 \mathrm{~Pa}$ (Fig. 3a) and was mostly positive (onshore) with short periods of offshore winds. Along-shelf winds were dominantly from north (negative values of along-shelf wind stress), with episodic and weaker events of southerly winds (Fig. 3b). Along-shelf wind stress $\left(\tau_{s}^{y}\right)$ was overall higher than cross-shelf wind stress, and ranged between $-0.1 \mathrm{~Pa}$ and $0.05 \mathrm{~Pa}$.

\subsubsection{Waves and tides}

Throughout the 3 summers the waves had a mean significant wave height of $1.2 \mathrm{~m}$ (Fig. 3c) and significant wave heights above $2.5 \mathrm{~m}$ were rare during this period. As seen in Lentz et al. (2008) and Fewings et al. (2008), wave-driven cross-shelf currents for waves with Hsig $1.2 \mathrm{~m}$ are in the order of $0.01 \mathrm{~m} \mathrm{~s}^{-1}$, and directed offshore (wave-driven undertow). The tidal components were diagnosed using the tidal gauge data and the T_TIDE package (Pawlowicz et al., 2002). The dominant tidal component was the M2 (lunar semidiurnal tide, with period of $12.42 \mathrm{~h}$ ) followed by S2, 

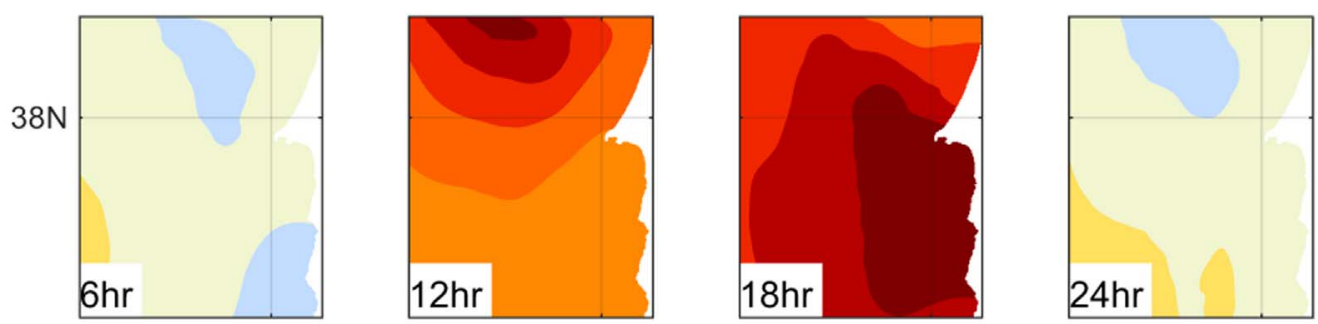

$\left\{\begin{array}{l}0.1 \\ 0.08 \\ 0.06 \\ 0.04 \\ 0.02\end{array}\right.$
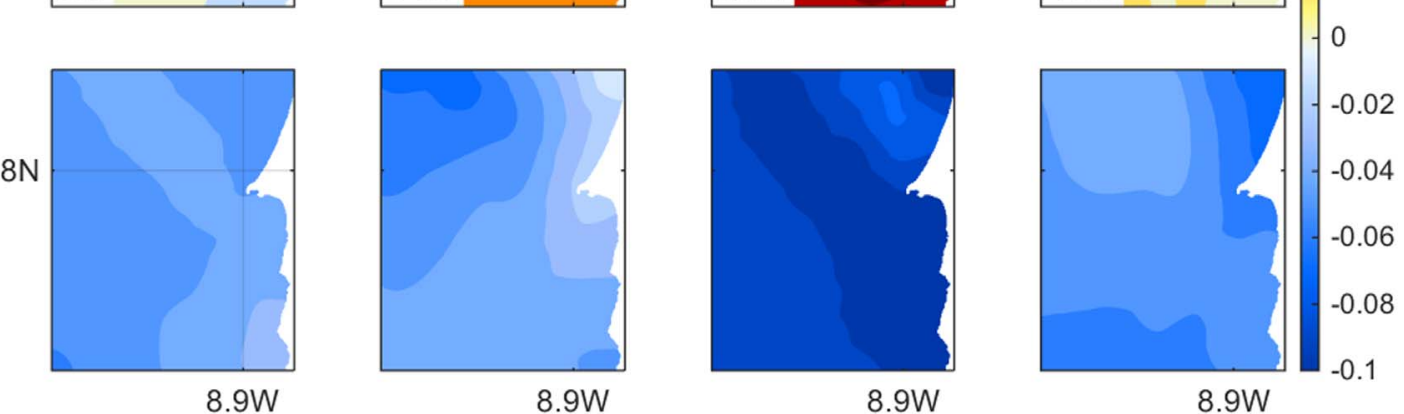

๘

$8.9 \mathrm{~W}$

$8.9 \mathrm{~W}$

$8.9 \mathrm{~W}$

$8.9 \mathrm{~W}$

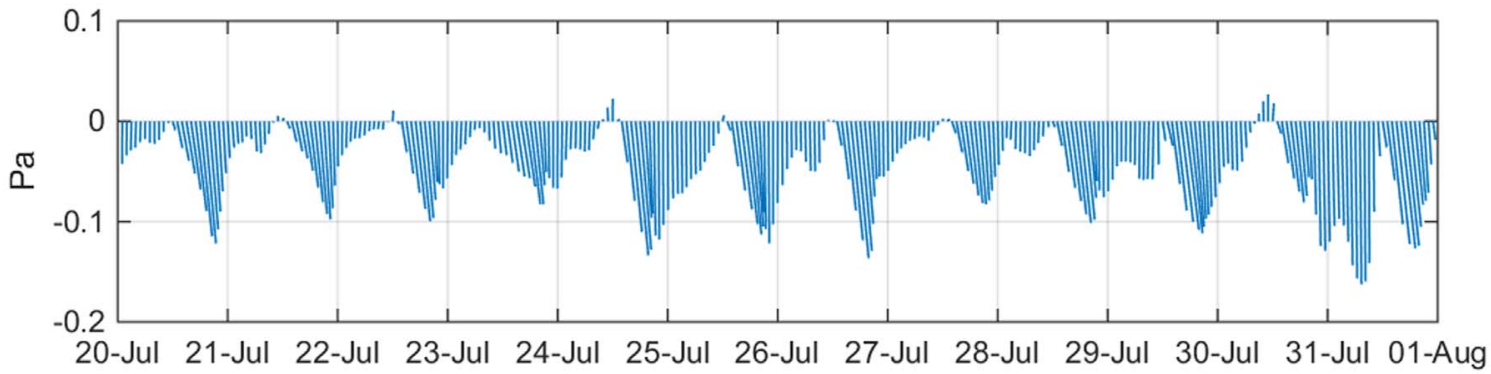

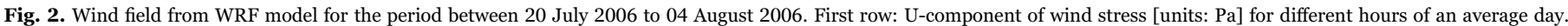
Second Row. V-Component of wind stress [units: Pa] for different hours of an average day. Bottom Row: Wind vectors for the 15-day run at the ADCP site.

N2 (semidiurnal) and K1 (diurnal tide). The mean tidal amplitude at this site, during these 3 summers, was $1.7 \mathrm{~m}$ with maximum of $3.6 \mathrm{~m}$ (Fig. 3d). Estimations of the barotropic tidal contribution of the M2 tide resulted in cross-shelf velocities around $2 \times 10^{-3} \mathrm{~m} \mathrm{~s}^{-1}$.

\subsubsection{Stratification}

Throughout the period when water temperature was measured, the water column was stratified (Fig. 3e). A mean difference between surface and bottom temperature of $2{ }^{\circ} \mathrm{C}$ was observed, which is considered high stratification for a 12-m depth site (Lentz, 2001;
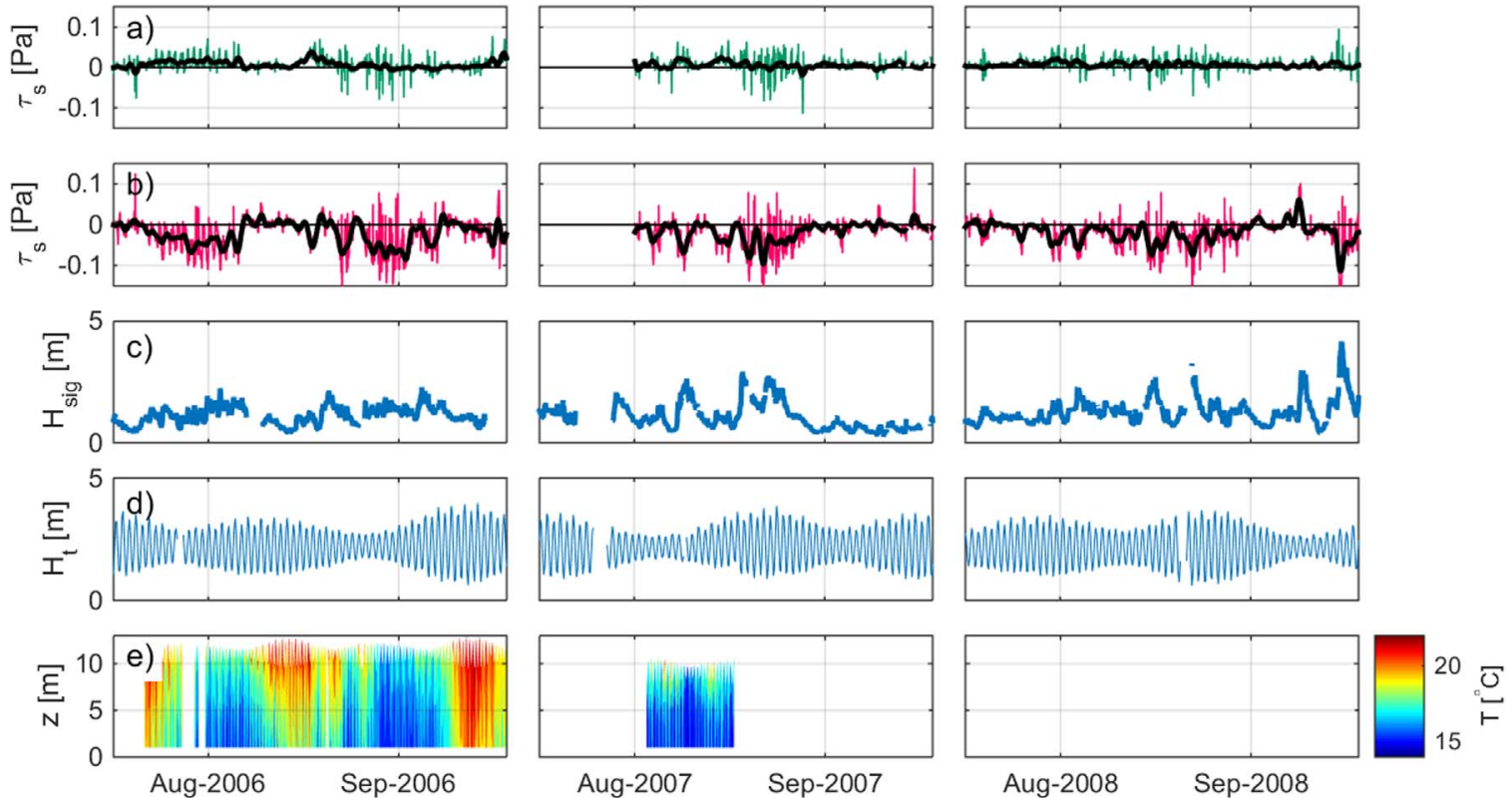

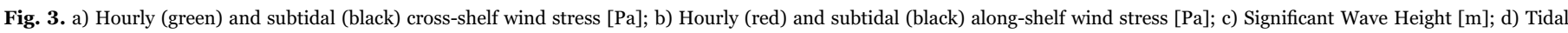

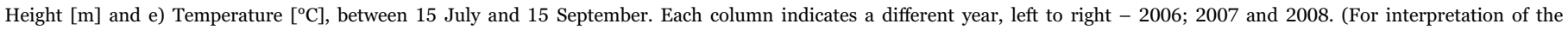
references to color in this figure legend, the reader is referred to the web version of this article.) 

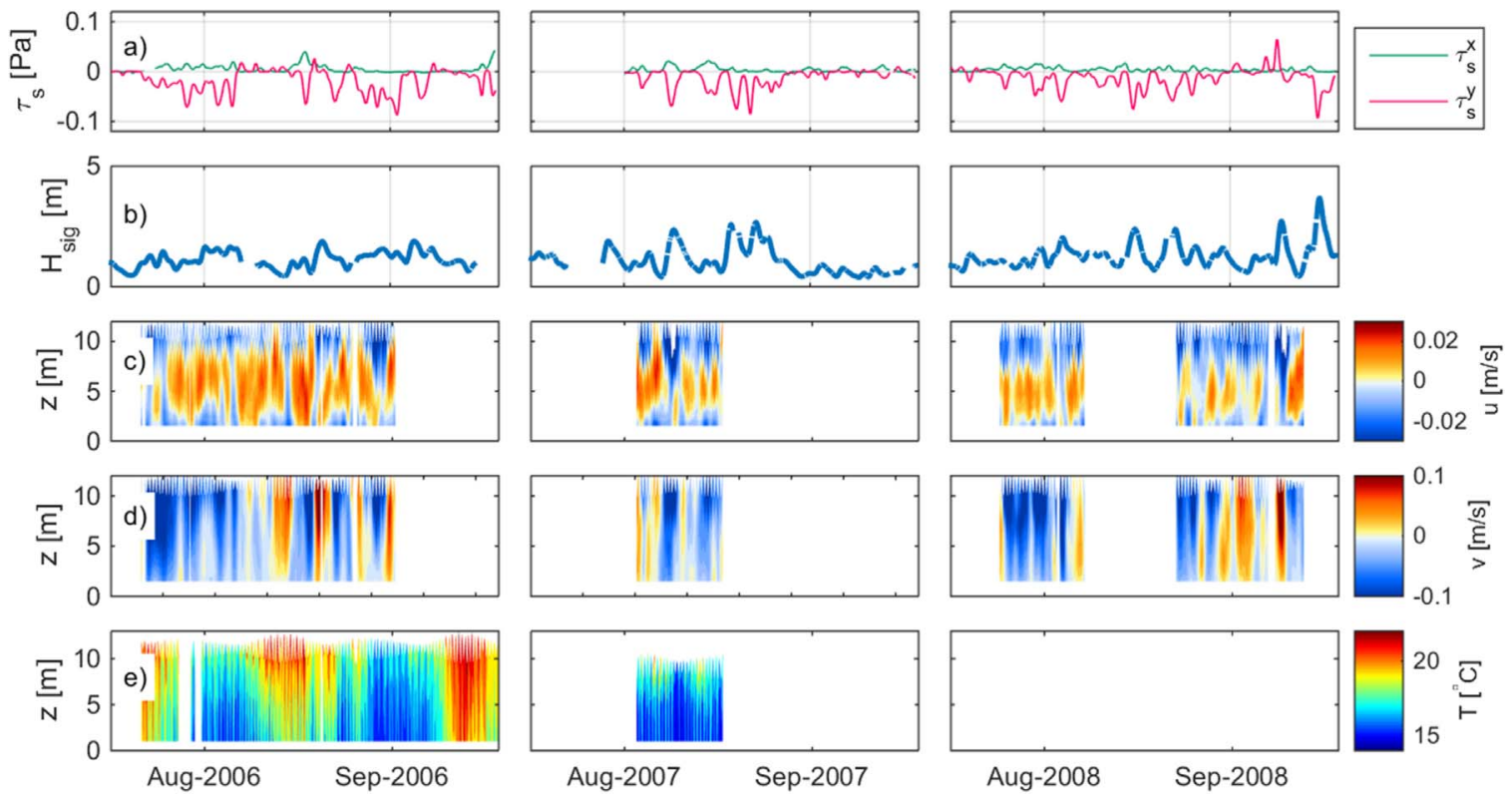

Aug-2008 Sep-2008

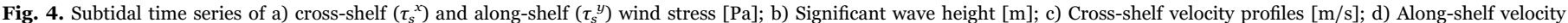
profiles $[\mathrm{m} / \mathrm{s}]$; and e) Temperature profiles $\left[{ }^{\circ} \mathrm{C}\right]$. Each column, left to right $-2006 ; 2007$ and $2008 . \mathrm{z}=0$ is the bottom.

Durski et al., 2004). Temperature changes are apparently connected with the variability of the along-shelf winds, with higher stratification periods occurring during relaxation of the northerly winds. However, periods of higher surface temperatures are also concurrent with spring tides, meaning that tidal effects on the stratification should not be neglected.

\subsubsection{Mean circulation}

During the summers of 2006, 2007 and 2008, the subtidal along-shelf velocity (Fig. 4d) was southwards, consistent with a response to northerly, upwelling-favourable winds, which is a typical wind regime in the Western Iberian margin during summer
(Relvas et al., 2007). There were a few events where the upwelling relaxed and the wind rotated northwards. During those events, the along-shelf velocity was northwards. The intensity of the alongshelf velocity was stronger at the surface and decayed with depth. The cross-shelf velocity (Fig. 4c) had a persistent maximum onshore flow at mid-depth, with offshore velocities at surface and bottom. This parabolic profile did not change regarding northerly or southerly winds, except during strong upwelling-favourable wind conditions, when the cross-shelf velocity showed a two-layer vertical structure with offshore velocities at surface and an opposite flow in depth, as should be expected during upwelling conditions.
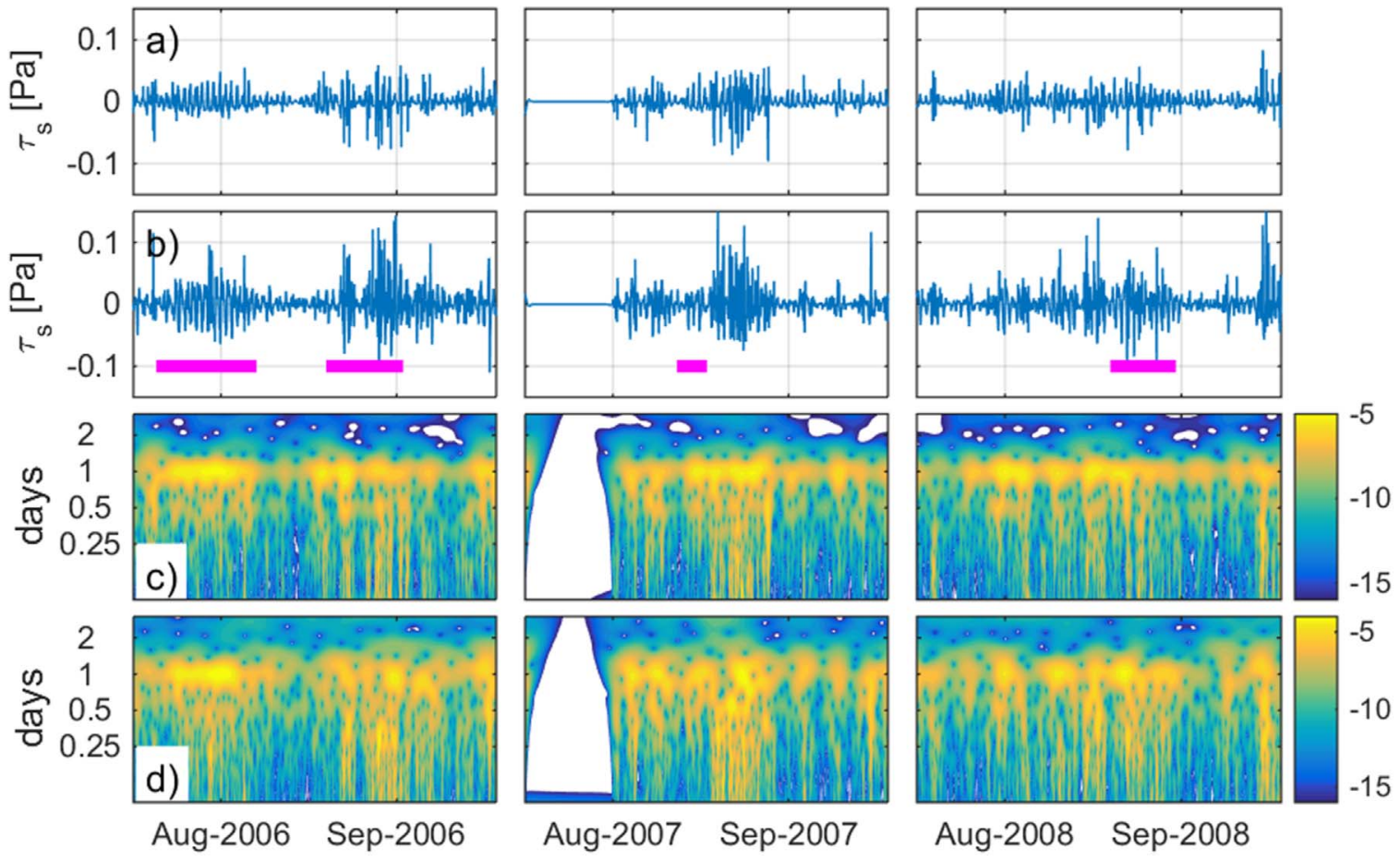

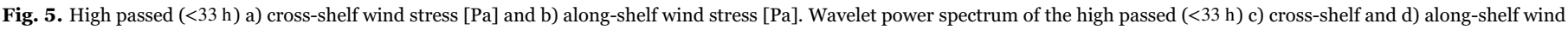
stress. Magenta lines in b) represent the periods of strong diurnal cycle (considering the periods when ADCP data was collected). 

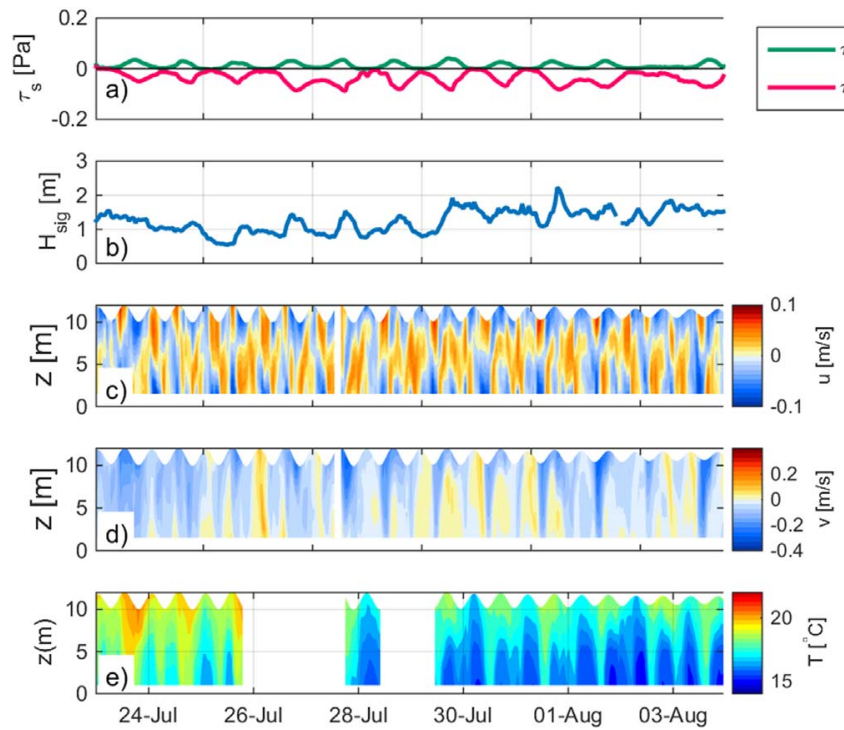

Fig. 6. Time series, between 20 July and 04 August 2006, of a) Wind stress [Pa]; b) Significant wave height [m]; c) Cross-shelf velocity [m/s]; d) Along-shelf velocity [m/s]; and e) Temperature $\left[{ }^{\circ} \mathrm{C}\right] . \mathrm{z}=0$ is the bottom.

\subsubsection{Circulation at diurnal timescales}

Throughout this study, it was given special attention to the diurnal variability of the circulation. A method defined by Hendrickson and MacMahan (2009) as the '24-h time-averaged' was used. The result consists of an average day (hereinafter clock-hour average day) in which each hour corresponds to a mean of that same hour throughout a chosen period (example: hour 1 is an average of every 1:00 a.m. for a chosen period).

Spectral wavelet analysis (Morlet) at diurnal timescales $(<33 \mathrm{~h}$ with $95 \%$ of confidence level) of the observed wind stress shows that the highest energy is found in the diurnal period (Fig. $5 \mathrm{c}$ and d), and was consistent throughout the summers of 2006, 2007 and 2008. The stronger diurnal signals were found in the following periods: 20 July to 04 August 2006, 18-29 August 2006, 11-14 August 2007 (the strong diurnal signal remained until 23 of August but there is no ADCP data after day 14) and 18-27 August 2008. These periods are marked in Fig. $5 \mathrm{~b}$ and were the ones selected to compute the clock-hour average day of the current velocity and temperature profiles, wind parameters and wave height.

Emphasis was given to the period between 20 July to 04 August 2006 (hereinafter control period) when both wind and wave forcing maintained similar conditions (Fig. 6). The wind had a very steady pattern of northwesterly wind modulated by a diurnal oscillation of magnitude in both wind components (Fig. 6a). Wave height increased on average throughout this period but had a daily maximum concurrent with the maximum of wind magnitude (Fig. 6b). During this period, the cross- and along-shelf velocity (Fig. $6 \mathrm{c}$ and d, respectively) showed a repetitive circulation pattern. The flow in the along-shelf direction was southwards with a daily intensification in the afternoon. There was a daily flow reversal in the cross-shelf circulation at mid-day. Cross-shelf velocities ranged from 0.1 to $-0.1 \mathrm{~m} \mathrm{~s}^{-1}$ while the alongshelf circulation was stronger, reaching $-0.3 \mathrm{~m} \mathrm{~s}^{-1}$. The water column remained stratified during this period, with a marked diurnal heating and an overall decrease in temperature towards the end of July and beginning of August (Fig. 6e).

Results for the clock-hour average day over the control period are plotted in Fig. 7. The diurnal sea-breeze cycle is clear in the wind stress plots (Fig. 7a). Wind stress was weak in the morning period, but around $11 \mathrm{~h}$ there was an increase of both components of the wind stress, with cross-shelf wind stress peaking at $16 \mathrm{~h}$ and along-shelf wind stress at $18 \mathrm{~h}$. There was a decrease in $\mathrm{H}_{\text {sig }}$ throughout the
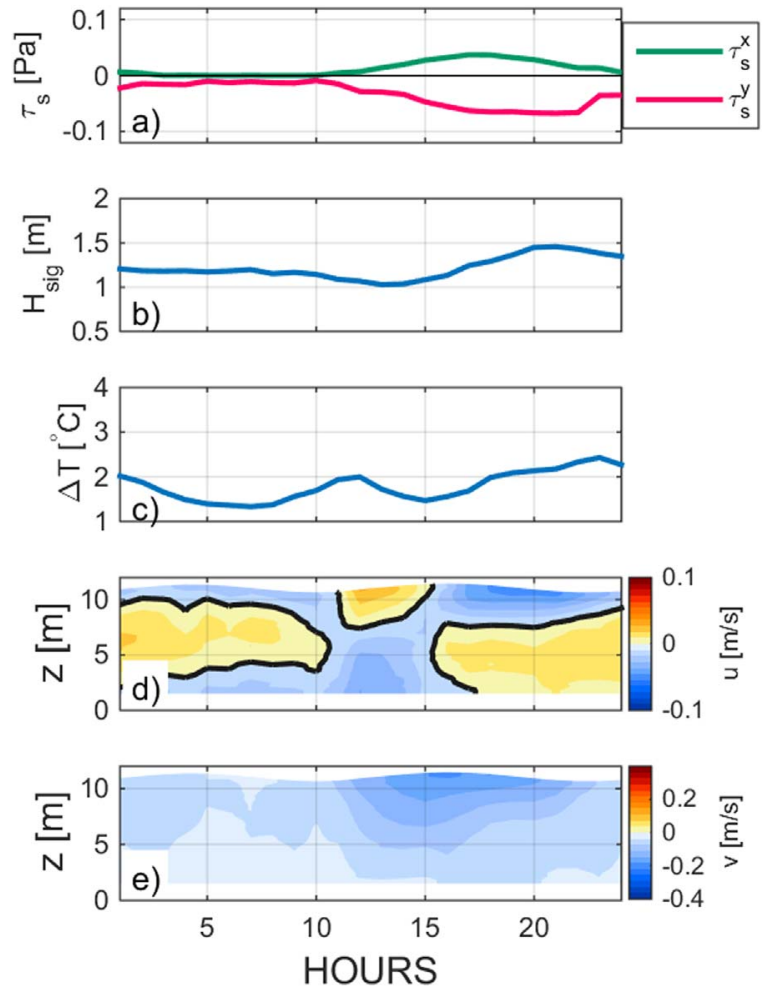

Fig. 7. The clock-hour average day, from July 20 to August 04, 2006, of a) Wind stress [Pa]; b) Significant wave height [m]; c) Difference between temperature at the surface and at the bottom $\left[{ }^{\circ} \mathrm{C}\right]$; d) Cross-shelf velocity $[\mathrm{m} / \mathrm{s}]$; e) Along-shelf velocity $[\mathrm{m} / \mathrm{s}] . \mathrm{z}=0$ is the bottom. Thick black line marks zero and the contour interval is $0.01 \mathrm{~m} / \mathrm{s}$.

morning and mid-day, with minimum height at $13 \mathrm{~h}$. Afterwards, the significant wave height increased, peaking at $20 \mathrm{~h}$ (Fig. 7b). A lag between wind and wave maximum was also described in Hendrickson and MacMahan (2009). The stratification (Fig. 7c) was present throughout the day with a semi-diurnal peak and higher values late in the day, related to diurnal heating. In the cross-shelf flow we can clearly identify 3 periods (Fig. 7 d). From $00 \mathrm{~h}$ to $11 \mathrm{~h}$ (morning period) the cross-shelf velocity had a 3-layer structure, with offshore velocities of approximately $-0.01 \mathrm{~m} \mathrm{~s}^{-1}$ at the surface and near the bottom, and an onshore flow at mid-depth. Between $12 \mathrm{~h}$ and $15 \mathrm{~h}$ (mid-day period), when wave height reached its minimum value and the wind increased in magnitude and rotated onshore, there was a reversal in the cross-shelf flow structure. The cross-shelf velocity profile had a 2-layer structure, with onshore flow in the surface layer, and offshore flow at the bottom (Fig. 7d). After $15 \mathrm{~h}$ (evening period), the velocity profile was again reversed, with onshore flow near the bottom and offshore flow at the surface, much stronger than in the morning period. This period corresponds to maximum wave height and strongest wind magnitude with a clear cross-shelf component. Throughout the clockhour average day the along-shelf velocity was always negative (Fig. 7e) with maximum velocities between $16 \mathrm{~h}$ and $18 \mathrm{~h}$, concurrent with the maximum of northerly wind. Overall, the cross-shelf circulation magnitude was around $0.01 \mathrm{~m} \mathrm{~s}^{-1}$, and the along-shelf circulation was much stronger, reaching up to $0.2 \mathrm{~m} \mathrm{~s}^{-1}$.

To show consistency of the diurnal variability observed for the control period, we computed the clock-hour average day over four periods when the diurnal cycle of wind in either component was also strong (shown as magenta lines in Fig. 5b). It can be seen in Fig. 8 that the averaged diurnal variability for these periods is much similar to the clock-hour average day of the control period. The cross-shelf circulation (Fig. 8d) also showed a daily three-period variability, although with a weaker magnitude than the clock-hour average day for the control period. The diurnal variability of the along-shelf velocity was 

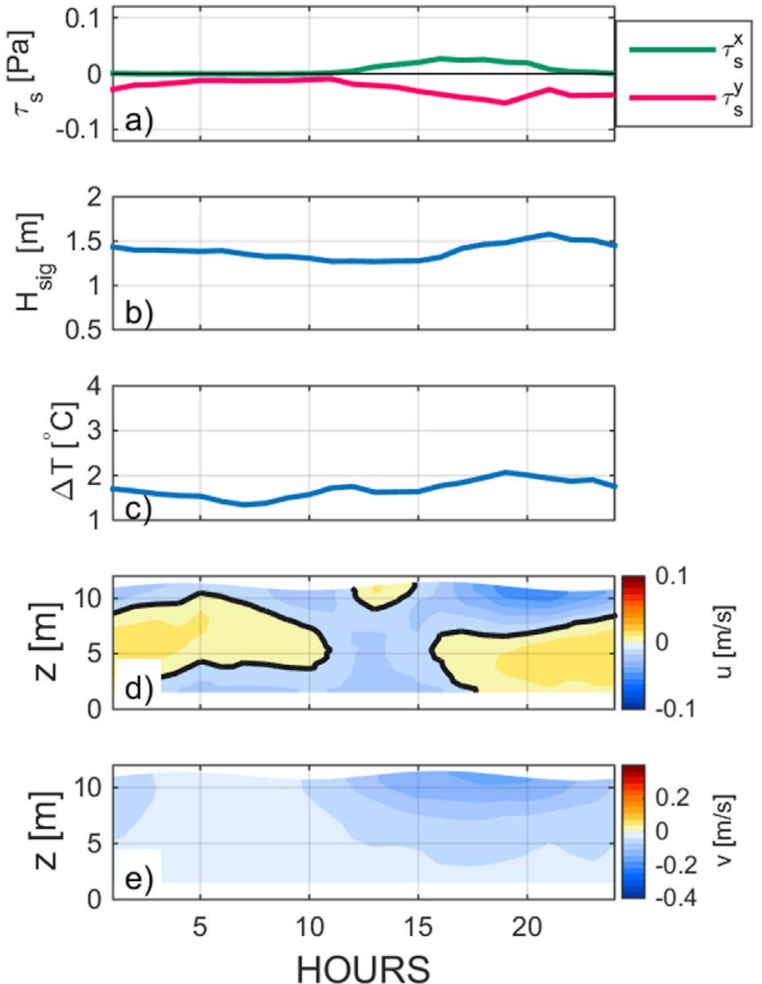

Fig. 8. The clock-hour average day, for the four periods of the three summers with a strong diurnal cycle of the wind marked in 5), of a) Wind stress [Pa]; b) Significant wave height $[\mathrm{m}]$; c) Difference between temperature at the surface and at the bottom $\left[{ }^{\circ} \mathrm{C}\right]$; d) Cross-shelf velocity $[\mathrm{m} / \mathrm{s}]$; e) Along-shelf velocity $[\mathrm{m} / \mathrm{s}] . \mathrm{z}=0$ is the bottom.

also similar to the control period, with maximum (although slightly weaker) southwards flow near the surface and in the evening, concurrent with maximum wind magnitude.

\subsection{Model results}

\subsubsection{Model-data comparison}

Model results for the grid point nearest to the ADCP site are used for comparisons with in-situ data. Overall, the model simulated successfully most features of the circulation and temperature evolution at the ADCP site (Fig. 9). The wind undergoes a diurnal cycle of both magnitude and direction, rotating onshore with increasing magnitude at the end of each day (Fig. 9a). In the cross-shelf direction (Fig. 9b), the circulation shows a permanent two-layer structure, with a repetitive
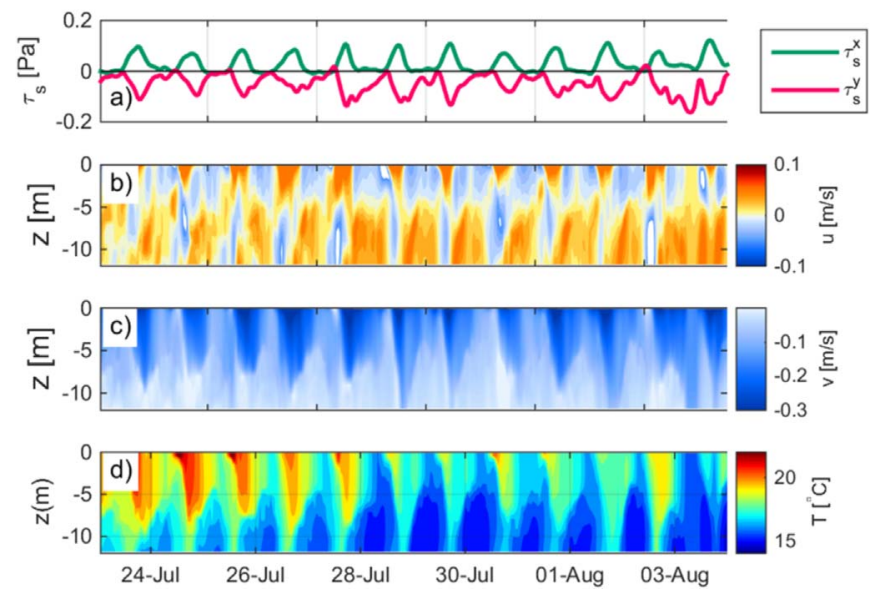

Fig. 9. Modelled time series of a) Wind stress [Pa]; b) Cross-shelf [m/s]; c) Along-shelf velocity $[\mathrm{m} / \mathrm{s}]$; d) Temperature profiles $\left[{ }^{\circ} \mathrm{C}\right]$, at the $\mathrm{ADCP}$ site.
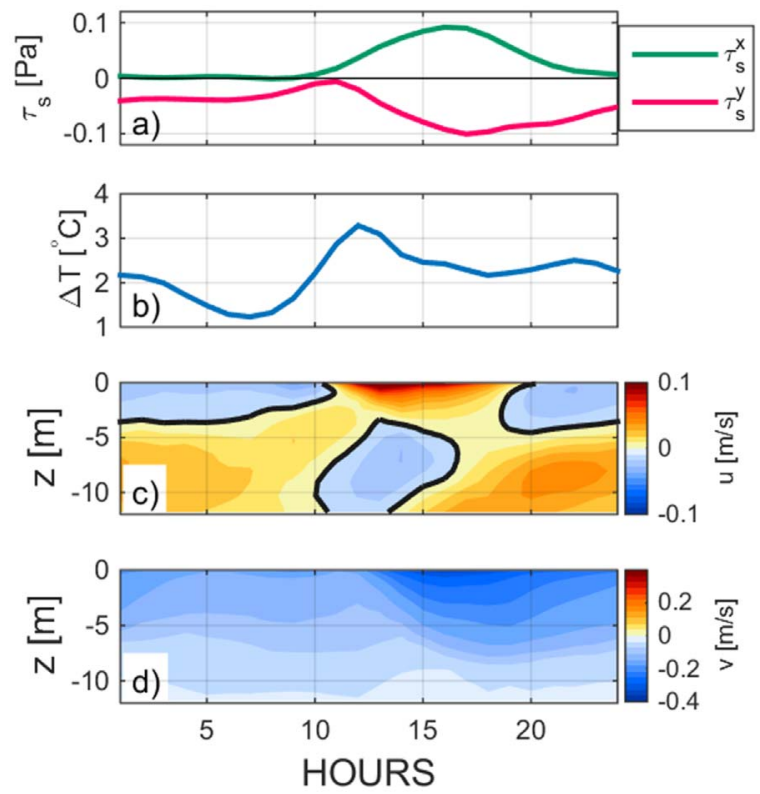

Fig. 10. Modelled clock-hour average day of a) Wind stress $[\mathrm{Pa}]$; b) Temperature difference between surface and bottom $\left[{ }^{\circ} \mathrm{C}\right]$; c) Cross-shelf velocity $[\mathrm{m} / \mathrm{s}]$; d) Along-shelf velocity $[\mathrm{m} / \mathrm{s}]$, at the ADCP site. Thick black line marks zero and the contour interval is $0.01 \mathrm{~m} / \mathrm{s}$.

daily cycle of flow reversal of the entire water column at mid-day. The along-shelf velocity (Fig. 9c) is always southwards, intensified at the surface, and with a daily increase of magnitude later in the day (concurrent with the daily maximum of wind magnitude). The water column is stratified at all times (Fig. 9d), with stronger stratification in the first 5 days and again in August 02. The 12-day average difference between surface and bottom temperature was $2.2{ }^{\circ} \mathrm{C}$, consistent with the observations.

We then computed the clock-hour average day for the same variables. The results are shown in Fig. 10. The model represents well the observed diurnal cycle of wind and stratification (Fig. 10a and b, respectively) showing the wind variability and the temperature average difference of around $2{ }^{\circ} \mathrm{C}$ between the surface and bottom layer. For the cross-shelf circulation (Fig. 10c) the reversal at mid-day is present, with longer duration than in the observations, and the upwelling-type exchange in the evening is also reproduced. The along-shelf velocity (Fig. 10d) has the same structure and variability as the observations, with surface intensified southward velocities and an increase in magnitude in the afternoon.

The model results are about $20-30 \%$ stronger than the observations for both velocity components, except for the offshore (cross-shelf negative) values which are about $10 \%$ weaker.

\subsubsection{Circulation in the vicinity of the Cape}

Fig. 11 shows the horizontal fields of surface temperature (top row) and surface elevation (bottom row) with current velocity vectors superimposed (surface temperature and velocity correspond to the average of the first $5 \mathrm{~m}$ ) for six different hours of the clock-hour average day: $4 \mathrm{~h}, 8 \mathrm{~h}, 12 \mathrm{~h}, 16 \mathrm{~h}, 20 \mathrm{~h}$ and $24 \mathrm{~h}$. The blue vectors represent the wind at the $\mathrm{ADCP}$ site for the corresponding hour.

Fig. 11 clearly illustrates the influence of the cape on the temperature and surface elevation fields. The permanence of northerly wind maintains a background upwelling circulation throughout the domain. In the northside of the cape, the largest southward currents, associated with the upwelling-jet, are concentrated from the coast to the $50-\mathrm{m}$ isobath. The presence of the cape causes the deflection of this jet to the west. The upwelling jet is then displaced offshore and follows the 100$\mathrm{m}$ isobath after the cape. As the upwelling-jet is deflected by the cape, it rotates cyclonically. The deviation of the upwelling jet by the cape leads 

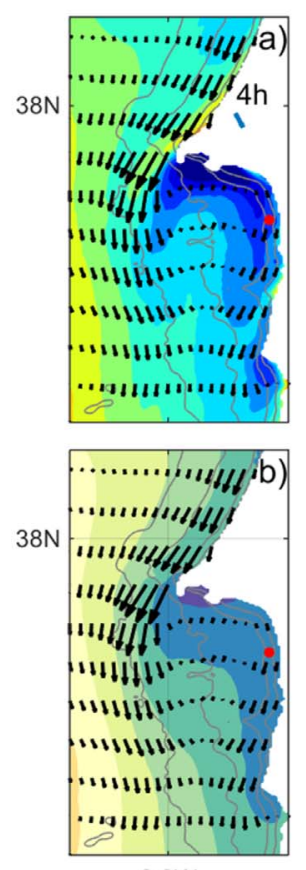

$8.9 \mathrm{~W}$
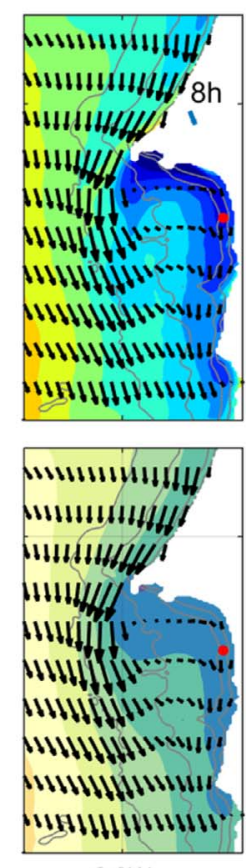

$8.9 \mathrm{~W}$
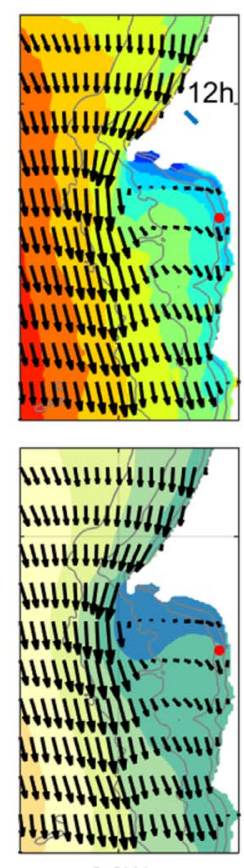

$8.9 \mathrm{~W}$
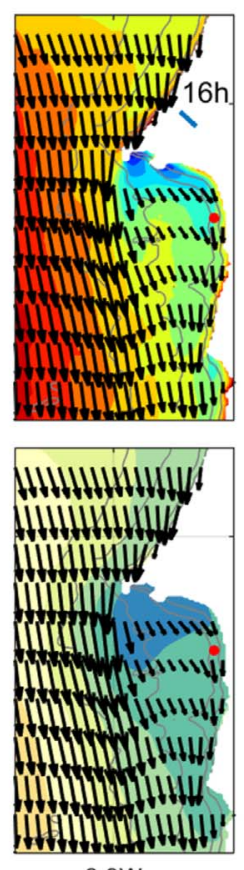

$8.9 \mathrm{~W}$
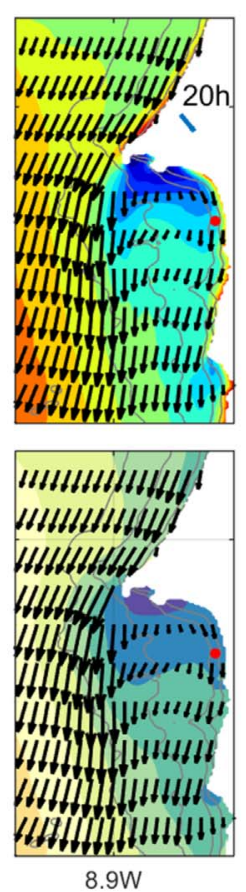
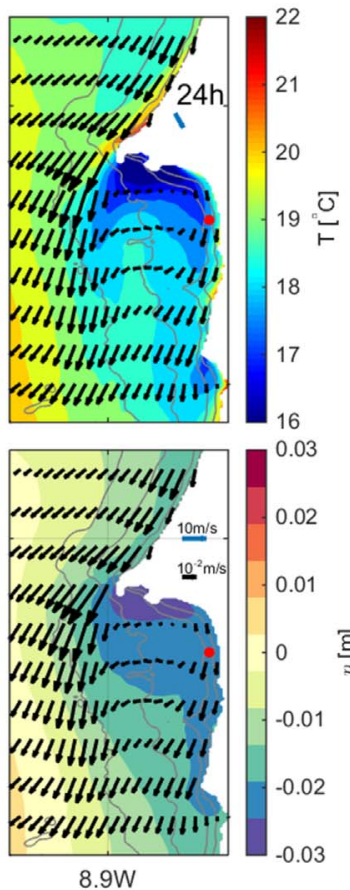

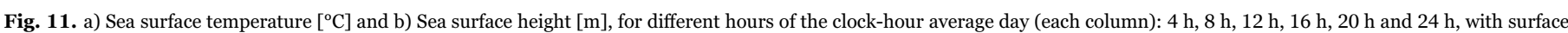

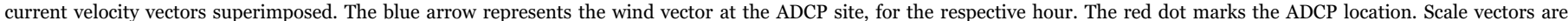
represented in the last subfigure. (For interpretation of the references to color in this figure legend, the reader is referred to the web version of this article.)

to lowering the sea surface elevation south of the cape. Similar to the surface elevation, lowest temperatures are seen south of the cape. In a region just below Cape Sines, the circulation is weaker and the crossshelf component is slightly dominant.

In our case, superimposed to a constant upwelling-favourable wind regime there is also a daily oscillation of the wind magnitude and direction, which will have different impact on the circulation depending on the region considered. Overall the circulation is dominantly to the south, with a weaker zonal component that rotates from west to east and again to west throughout the day.

In the northside of the cape, the upwelling-jet is constrained by the presence of the coast. While most of the flow rotates to the east, the circulation aligns with the bathymetry as we approach the coast, causing a circulation convergence (downwelling), which results in a region of warmer waters near the coast in the afternoon.

In the leeside of the cape the flow becomes meridionally aligned, forming a secondary upwelling-jet within $5 \mathrm{~km}$ of the coast. This secondary upwelling flow is dominantly southwards but has a weak zonal component that alternates from westwards in the morning period, to eastwards at mid-day and finally to westwards later in the day. This is consistent with the surface flow reversal observed at the $\mathrm{ADCP}$ location (a red dot representing the ADCP location can be seen in Fig. 11 over this secondary upwelling flow). The two upwelling jets are also responsible for the southwards advection of the cooler, newly upwelled waters from the south part of the cape (Fig. 11 top).

\subsubsection{Regions with similar diurnal variability}

We proceeded to the analysis of whether the circulation observed by the ADCP is local or if it is representative of a region in the leeside of the cape.

The distinct circulation feature identified in the present study is the cross-shelf current reversal at mid-day. For that reason, we analyse how the circulation varies along the domain. We are interested in regions where the velocity at surface and bottom show the flow reversals at the same hours as in the observations, which are in agreement with the wind variability.

To achieve that, we searched for grid points in the model results with similar characteristics by producing binary maps. These maps were based on the direction of the zonal flow at the surface and bottom layers, and were constructed according to the following rules: i) For each grid point, the signal of the zonal component of the velocity in both layers is compared; ii) In the morning and evening, we searched for regions where the surface velocity was negative (offshore at the ADCP site), and bottom velocity was positive (onshore), for the mid-day period we searched for the opposite onshore flow in the upper layer and offshore flow in the bottom layer. Whenever these conditions are met, the value on the map is one and for any other situation the value is zero. Note that the 3-layer structure observed in the morning period was not reproduced by the model, and therefore, in the morning period, the circulation pattern considered was the same as the model simulated (2-layer flow).

The binary map for the set of hours: $8 \mathrm{~h}, 12 \mathrm{~h}$ and $24 \mathrm{~h}$, for regions with depth less than $50 \mathrm{~m}$, is shown in Fig. 12, where red represents 1 and white is 0 . We show separately the binary maps representing the surface layer (top row), the bottom layer (middle row) and the combination of both (bottom row) for analysis purposes. Thus, the top row of Fig. 12 shows the regions where the surface (top $5 \mathrm{~m}$ ) cross-shelf velocity was negative (offshore) at $8 \mathrm{~h}$ (a), positive (onshore) at $12 \mathrm{~h}$ (b) and again negative at $24 \mathrm{~h}$ (c). The middle row is analogous for the bottom layer (last $5 \mathrm{~m}$ ) but with opposite signal: positive cross-shelf velocity at $8 \mathrm{~h}$, negative at $12 \mathrm{~h}$ and positive at $24 \mathrm{~h}$. The right column in Fig. 12 (d) shows the product of the previous three ( $a, b$ and $c)$. The bottom row is the combination of the surface and bottom layer, showing in red the regions where the cross-shelf flow in both layers has a similar vertical structure as the model at the ADCP site.

In the surface layer, at $8 \mathrm{~h}$ (Fig. 12a; top row), only a small region south of Cape Sines has negative velocities at the surface. This zone is limited to a small along-shelf band near the coast where the coast becomes meridionally aligned (consistent with the location of the secondary upwelling jet). On the other hand, at $12 \mathrm{~h}$ (Fig. 12b, top row) a great part of the domain is marked in red, showing that most of the domain (considering depths below $50 \mathrm{~m}$ ) has positive zonal velocities. Lastly, at $24 \mathrm{~h}$ (Fig. 12c, top row), most of the shallow part of the domain $(<50 \mathrm{~m})$ has negative velocities at the surface, with the exception of a small region south of Cape Sines.

It is clear that, at the surface, eastwards flow at mid-day and westwards 


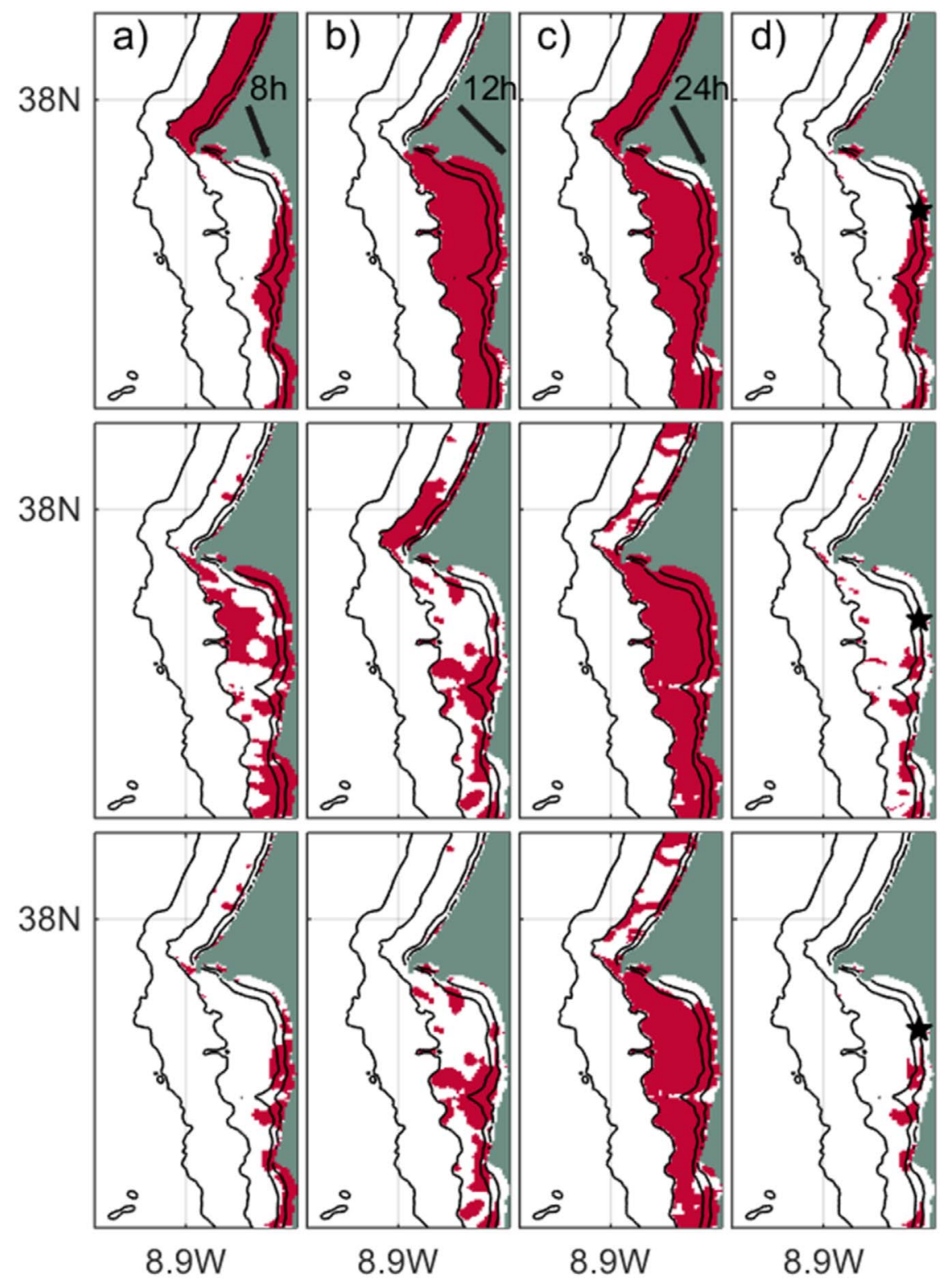

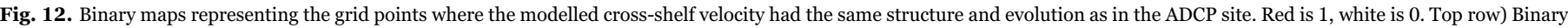

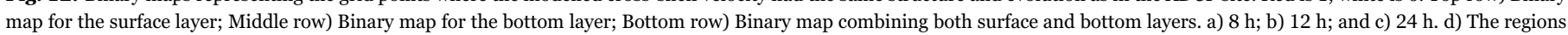

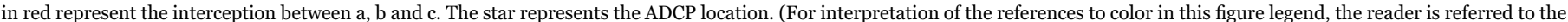
web version of this article.)

flow in the evening are common circulation features in a large portion of the domain but only a small region, consistent with the location of the secondary upwelling jet, has negative velocities in the morning period. This implies that only the region over the secondary upwelling jet has the same daily evolution of the surface flow as the model at the ADCP site (Fig. 12; top row; map d). It is visible in Fig. 12 that the marked regions in the morning (a) and mid-day (b) hours on the bottom layer (middle row) are sparse and connected with small-scale topographic variations. However, at $24 \mathrm{~h}$ (c) most part of the domain (for depths below $50 \mathrm{~m}$ ) show positive velocities.

Combining the binary maps of both surface and bottom layer (bottom row of Fig. 12) results in few regions with a behaviour synchronous with the observations, mainly due to the small scale variations in the bottom layer. The analysis of the last map indicates that only a few zones fit our criteria and, by definition, the ADCP site is included (marked as a star in Fig. 12). The resulting map shows that these zones are located in the shallow region south of cape Sines, when the coast becomes meridionally aligned, consistent with the location of the secondary upwelling jet.

\section{Discussion and conclusions}

Nearshore circulation was analysed using ADCP data collected at 12-m in the lee of Cape Sines (Fig. 1), during the summers of 2006, 2007 and 2008. The region is under persistent upwelling-favourable wind conditions modulated by a daily cycle similar to sea breeze. We focused on a 15-day period between 20 July to 04 August of 2006, when the wind maintained similar conditions, to study the diurnal variability of the cross-shelf circulation.

The daily variability of the observed cross-shelf circulation consists of three distinct periods. A morning period with a 3-layer structure with onshore velocities at mid-depth, a mid-day period where the flow is reversed and has a 2-layer structure with onshore velocities at surface and offshore flow at the bottom (downwelling), and, lastly, a 2-layer period, with strong offshore velocities at the surface and onshore flow at the bottom (upwelling).

The observed cross-shelf circulation showed a peculiar vertical shape and diurnal variability different from several other systems 
described in literature. Most inner-shelf studies admit that cross-shore wind stress may induce a circulation of similar magnitude as upwelling or downwelling, specifically over stratified waters. Cross-shore wind stress is found to force a circulation of same direction as wind (onshore or offshore) in the surface layer and a compensating opposite flow underneath (Lentz and Fewings, 2012). Although previous works have found that the cross-shelf circulation is strongly modified by sea breeze events, the observed 3-period clock-hour average day described here is different from previous studies (Woodson et al., 2007; Hendrickson and MacMahan, 2009; Xiaoqian Zhang et al., 2010). Hendrickson and MacMahan (2009) described a diurnal circulation forced by sea breeze. In their study, the most clear feature was a wave-driven undertow forced by the sea breeze effect on wave height. They found that a wind stress threshold of $0.5 \mathrm{~Pa}$ was needed to modify the background circulation. We do not observe that type of circulation, probably due to lower $\mathrm{H}_{\text {sig }}$ and wind stress present at this location. Except for the upwelling-type cross-shelf circulation in the evening period, the observed diurnal circulation did not show a simple wind- or wavedriven circulation coherent to previous inner-shelf studies (Tilburg, 2003; Kirincich et al., 2005; Fewings et al., 2008; Lentz et al., 2008; Hendrickson and MacMahan, 2009; Lentz and Fewings, 2012).

A distinctive feature of the circulation at this site appears to be the parabolic cross-shelf profile, with maximum onshore velocity at middepth, that also appears in the morning period of the clock-hour average-day. (Lentz and Chapman, 2004) showed that for strong stratification conditions, the onshore return flow (as response to upwelling) can be in the interior of the water column, as a response to increasing momentum flux divergence and small bottom stress in the momentum balance. Mid-shelf studies on the Middle Atlantic Bight (Lentz, 2008) and Oregon coast (McCabe et al., 2015) showed mean cross-shelf profiles with maximum onshore flow at mid-depth which were explained by a combination between wind stress and local alongshelf pressure gradients. In a study around Point Conception, California, Fewings et al. (2015) consistently observed vertical profiles of the same form, which were associated with pressure gradients connected with local wind relaxations. These studies indicate that the along-shelf pressure gradient is likely a key factor in the cross-shelf vertical profile form at this site.

The realistic model was forced exclusively with local winds and simulated most of the current variability seen at the ADCP site, including the mid-day flow reversal and the upwelling-type circulation in the evening. This supports the hypothesis that the observed crossshelf circulation pattern at diurnal timescales is mostly wind-driven. The observed two-layer pattern in the evening (after $19 \mathrm{~h}$ ) is consistent with an upwelling circulation (Allen et al., 1995; Austin and Lentz, 2002). Although in shallow waters the circulation tends to align barotropically with the wind (Lentz, 2001; Kirincich et al., 2005), the presence of stratification enables the cross-shelf exchange to penetrate into shallower waters, as suggested in several studies (Lentz, 2001; Austin and Lentz, 2002; Durski et al., 2004; Kirincich et al., 2005). However, the model fails to reproduce the 3-layer structure seen in the morning. This can be due to the fact that other forcing elements may have a stronger impact in this period (like tides and or waves) or larger scale processes described before (Lentz, 2008; McCabe et al., 2015; Fewings et al., 2015) but not reproduced in the model due to the small domain.

Wave data collected at 98-m depth showed significant wave heights of less than $2 \mathrm{~m}$ for most part of the time (Fig. 3). At this point we can only speculate that the waves do not affect significantly the circulation since $\mathrm{H}_{\text {sig }} 1.2 \mathrm{~m}$ which corresponding wave forcing (cross-shelf velocities below $0.01 \mathrm{~m} \mathrm{~s}^{-1}$ ), is most likely not sufficiently energetic to modify the wind-driven circulation (Fewings et al., 2008; Lentz et al., 2008; Hendrickson and MacMahan, 2009).

Tidal forcing may have some significance in the circulation, especially in the morning period. A recent work by Trindade et al. (2016) that used the same model configuration as this study, but included tidal forcing, showed little differences between the modelled circulation during neap and spring tides. In their study, the model also failed to reproduce the 3-layer structure in the morning period. This further indicates that tides probably do not significantly affect the observed circulation.

Studies over different inner-shelves (Lentz et al., 1999; Liu and Weisberg, 2005; Fewings and Lentz, 2010) seem to agree that the circulation is mainly forced by along-shelf pressure gradient (generated by local wind forcing) and wind stress, though other processes can also be important depending on water depth and wave regime.

Several modelling studies (Austin and Lentz, 2002; Cudaback et al., 2005; Estrade et al., 2008; Marchesiello and Estrade, 2010; Tilburg, 2003) and observations (Lentz et al., 1999; Lentz, 2001; Kirincich et al., 2005; Fewings et al., 2008) found that along-shelf wind alone is not an efficient mechanism in driving cross-shelf exchange on innershelf. As seen in Gan and Allen (2002) and Kuebel Cervantes and Allen (2006), strong onshore flows in the leeside of the cape result from the interaction between the wind-driven flow and the variations in topography, which are responsible for the setting up of an along-shelf pressure gradient as a response to the decreased surface elevation in the leeside of a cape, which results from the intensification of the alongshelf velocity around the cape. A work by Sanay et al. (2008) over the inner-shelf showed that there is a 3-D circulation response to wind in the presence of a cape. Ganju et al. (2011) pointed out the importance of topographic features in the circulation over the inner-shelf by showing that the dynamical balance was dominated by pressure gradient and horizontal advection terms, which varied with subtle bathymetric changes. Finally, several studies found that non-linear advection is particularly important in the vicinity of topographic features (Doglioli et al., 2004; Meunier et al., 2010; Liu and Gan, 2014). It is expected that Cape Sines will have a similar effect on the circulation, which will promote the generation of localized wind-forced pressure gradients and enhance the cross-shelf exchange in the leeside of the cape.

The upwelling jet deflection and corresponding cyclonic circulation due to the presence of a cape and the intensified upwelling in the leeside of the cape is consistent with several studies (Barth et al., 2000; Gan and Allen, 2002; Doglioli et al., 2004; Kuebel Cervantes and Allen, 2006; Meunier et al., 2010; Perlin et al., 2011; Liu and Gan, 2014). However, most of these studies deal with steady upwelling regimes or with relaxation periods of more than one day, and do not describe the diurnal variability caused by a daily oscillating upwelling regime. In our case, the diurnal variability of the wind is felt differently across the domain and the small-scale spatial alternation of upwelling/downwelling regions can effectively drive cross-shelf exchange, especially in the leeside of Cape Sines.

In summary, in-situ data and the numerical model results helped to characterize the nearshore circulation in the vicinity of Cape Sines. We conclude that the presence of the cape is responsible for the observed cross-shelf circulation pattern but only very few regions show a similar flow evolution as the observations. The persistence of upwellingfavourable winds promoted retention of cold and newly upwelled waters in the leeside of Cape Sines which is significantly relevant for pythoplankton blooms and larvae development (Roughan et al., 2005a, 2005b, Peliz et al., 2007; Oliveira et al., 2009). The fact that the wind diurnally undergoes relaxation and intensification strongly modifies the cross-shelf circulation, promoting superficial onshore flows at midday, in the leeside of Cape Sines, that overpower the strong along-shelf currents. The combination of these two wind regimes indicates that the study region has effective mechanisms of onshore transport during this period, as seen in Trindade et al. (2016). The small-scale circulation patterns described here can be particularly helpful to understand the transport and settlement of larvae in this region and in other regions with similar topography and wind characteristics. 


\section{Acknowledgements}

We thank D. Jacinto and T. Silva for help during field work and the Port of Sines Authority (APS) for providing oceanographic and meteorological data. Financial support was provided by FCT (POCI/ MAR/57630/2004; PTDC/BIA-BEC/103734/2008 and PEst-OE/ MAR/UIO199/2011). The simulations were preformed in the computational facilities provided under FCT contract RECI/GEO-MET/0380/ 2012. Luísa Lamas was funded by the FCT under a Ph.D. grant (SFRH/ $\mathrm{BD} / 69533 / 2010)$.

\section{References}

Allen, J.S., Newberger, P.A., Federiuk, J., 1995. Upwelling circulation on the oregon continental shelf. Part I: response to idealized forcing. J. Phys. Oceanogr. 25, 1843-1866.

Austin, J., Lentz, S.J., 2002. The inner-shelf response to wind-driven upwelling and downwelling. J. Phys. Oceanogr. 32, 2171-2193.

Barth, J.A., Pierce, S.D., Smith, R.L., 2000. A separating coastal upwelling jet at Cape Blanco, Oregon and its connection to the California current system. Deep-Sea Res. II 47, 783-810.

Cruz, T., 1999. Settlement patterns of Chthamalus spp. at Praia da Oliveirinha (SW Portugal). Acta Oecol. 20, 285-287.

Cruz, T., Castro, J., Delany, J., McGrath, D., Myers, A., O'Riordan, R., Power, A.M., Rabaa, J., Hawkins, S., 2005. Tidal rates of settlement of the intertidal barnaclesChthamalus stellatus and Chthamalus montagui in western Europe: the influence of the night/day cycle. J. Exp. Mar. Biol. Ecol. 318, 5160.

Cruz, T., Oliveira, P., Fernandes, J., Angélico, M., Castro, J., Lima, N., Quintela, M., 2009. Final Report of project VERY NEAR Departures and Arrivals of Barnacle Larvaeonshore: Very Nearshore Physical Processes and Behaviour in SWPortugal (POCI/MAR/57630/2004).(Unpublished).

Cudaback, C.N.L., Washburn, L., Dever, E., 2005. Subtidal inner-shelf circulation near Point Conception, California. J. Geophys. Res. 110, C10007.

Doglioli, A.M., Griffa, A., Magaldi, M.G., 2004. Numerical study of a coastal current on a steep slope in presence of a cape: the case of the Promontorio di Portofino. J. Geophys. Res. 109, C12033.

Durski, S.M., Glenn, S.M., Haidvogel, D.B., 2004. Vertical mixing schemes in the coastal ocean: comparison of the level 2.5 Mellor-Yamada scheme with an enhanced version of the K profile parameterization. J. Geophys. Res. 109, C01015.

Estrade, P., Marchesiello, P., de Verdière, A.C., Roy, C., 2008. Cross-shelf structure of coastal upwelling: a two-dimensional extension of Ekman's theory and a mechanism for inner-shelf upwelling shut down. J. Mar. Res. 66, 589-616.

Fewings, M., Lentz, S.J., 2010. Momentum balances on the inner continental shelf at Martha's Vineyard coastal observatory. J. Geophys. Res. 115, C12023.

Fewings, M., Lentz, S.J., Fredericks, J., 2008. ADCP site of cross-shelf flow driven by cross-shelf winds on the inner continental shelf. J. Phys. Oceanogr. 38, 2358-2378.

Fewings, M., Washburn, S.L., Ohlmann, J.C., 2015. Coastal water circulation patterns around the Northern Channel Islands and Point Conception, California. Prog. Oceanogr. 138, 283-304.

Gan, J., Allen, J.S., 2002. A modeling study of shelf circulation off northern California in the region of the coastal ocean dynamics experiment: response to relaxation of upwelling winds. J. Geophys. Res. 107, C93123.

Ganju, N.K., Lentz, S.J., Kirincich, A.R., Farrar, J.T., 2011. Complex mean circulation over the inner shelf south of Marthas Vineyard revealed by ADCP site and a highresolution model. J. Geophys. Res. 116, C10036.

Gutierrez, B.T., Voulgaris, G., Work, P.A., 2006. Cross-shore variation of wind-driven flows on the inner shelf in Long Bay, South Carolina,United States. J. Geophys. Res. $111, \mathrm{C} 03015$.

Haidvogel, D., Arango, H., Budgell, W., Cornuelle, B., Curchitser, E., Di Lorenzo, E., Fennel, K., Geyer, W., Hermann, A., Lanerolle, L., Levin, J., McWilliams, J., Miller, A., Moore, A., Powell, T., Shchepetkin, A., Sherwood, C., Signell, R., Warner, J., Wilkin, J., 2008. Ocean forecasting in terrain-following coordinates: formulation and skill assessment of the regional ocean modelling system. J. Comp. Phys. 227, 3595-3624.

Hendrickson, J., MacMahan, J., 2009. Diurnal sea breeze effects on inner-shelf crossshelf exchange. Cont. Shelf Res. 29, 2195-2206.

Horwitz, R., Lentz, S.J., 2014. Inner-shelf response to cross-shelf wind stress: the importance of the cross-shelf density gradient in idealized numerical model and Field ADCP site. J. Phys. Oceanogr. 44, 86-103.

Jacinto, D., Cruz, T., 2008. Tidal settlement of the intertidal barnacles Chthamalusspp. in SW portugal: interaction between diel and semi-lunar cycles. Mar. Ecol. Prog. Ser. 366, 129-135.

Kirincich, A.R., Barth, J.A., Grantham, B.A., Menge, B.A., Lubchenco, J., 2005. Winddriven inner-shelf circulation off central Oregon during summer. J. Geophys. Res. 110, C10S03.
Kuebel Cervantes, A., Allen, J.S., 2006. Numerical model simulations of continental shelf flows off northern California. Deep-Sea Res. II 53, 2956-2984.

Lentz, S.J., 2001. The influence of stratification on the wind-driven cross-shelf circulation over the North Carolina shelf. J. Phys. Oceanogr. 31, 2749-2760.

Lentz, S.J., 2008. ADCP site and a model of the mean circulation over the Middle Atlantic Bight Continental Shelf. J. Phys. Oceanogr. 38, 1203-1221.

Lentz, S.J., Chapman, C., 2004. The importance of Nonlinear Cross-Shelf Momentum Flux during Wind-Driven coastal upwelling. J. Phys. Oceanogr. 34, 2444-2457.

Lentz, S.J., Fewings, M., 2012. Wind- and Wave-driven Inner-shelf Circulation. Annu. Rev. Mar. Sci. 14, 317-343.

Lentz, S.J., Guza, R.T., Fedderson, F., Herbers, T.H.C., 1999. Momentum balances on the North Carolina inner shelf. J. Geophys. Res. 226, 18205-18226.

Lentz, S.J., Fewings, M., Howd, P., Fredericks, J., Hathaway, K., 2008. ADCP site and a model of undertow over the inner continental shelf. J. Phys. Oceanogr. 38, 2341-2357.

Liu, Y., Weisberg, R.H., 2005. Momentum balance diagnoses for the West Florida shelf. Cont. Shelf Res. 25, 2054-2074.

Liu, Z., Gan, J., 2014. Modeling study of variable upwelling circulation in the East China Sea: response to a Coastal Promontory. J. Phys. Oceanogr. 44, 1078-1094.

Lucas, A.J., Pitcher, G.C., Probyn, T.A., Kudela, R.M., 2013. The influence of diurnal winds on phytoplankton dynamics in a coastal upwelling system off southwestern Africa. Deep-Sea Res. II 101, 50-62.

Marchesiello, P., Estrade, P., 2010. Upwelling limitation by geostrophic onshore flow. J. Mar. Res. 68, 37-62.

Marchesiello, P., McWilliams, J., Shchepetkin, A., 2001. Open boundary conditions for long-term integration of regional oceanic models. Ocean Model. 3, 1-20.

Maza, M., Voulgaris, G., Subrahmanyam, B., 2006. Subtidal inner shelf currents off Cartagena de Indias, Caribbean coast of Colombia. Geophys. Res. Lett. 33, L21606.

McCabe, R.M., Hickey, B.M., Dever, E.P., MacCready, P., 2015. Seasonal cross-shelf flow structure, upwelling relaxation, and the alongshelf pressure gradient in thenorthern California current system. J. Phys. Oceanogr. 45, 209227.

Meunier, T., Rossi, V., Morel, Y., Carton, X., 2010. Influence of bottom topography on an upwelling current: generation of long trapped filaments. Ocean Model. 35, 277-303.

Oliveira, P.B., Nolasco, R., Dubert, J., Moita, T., Peliz, A., 2009. Surface temperature, chlorophyll and advection patterns during a summer upwelling event off central Portugal. Cont. Shelf Res. 29, 759-774.

Pawlowicz, R., Beardsley, B., Lentz, S.J., 2002. Classical tidal harmonic analysis including error estimates in MATLABusing T_TIDE. Comput. Geosci. 28, 929-937.

Peliz, A., Marchesiello, P., Dubert, J., Marta-Almeida, M., Roy, C., Queiroga, H.H., 2007. A study of Crab Larvae Dispersal on the Western Iberian Shelf: physical processes. J. Mar. Syst. 68, 215-236.

Peliz, A., Boutov, D., Cardoso, R., Delgado, J., Soares, P., 2013. The Gulf of CadizAlboran sea sub-basin: model setup, exchange and seasonal variability. Oceanogr. Model. 61, 49-67.

Perlin, N., Skyllingstad, E.D., Samelson, R.M., 2011. Coastal atmospheric circulation around an Idealized Cape during wind-driven upwelling studied from a coupled ocean atmosphere model. Mon. Weather Rev. 139, 809-829.

Pineda, J., Reyns, N.B., Starczak, V.R., 2009. Complexity and simplification in understanding recruitment in benthic populations. Popul. Ecol. 51, 17-32.

Relvas, P., Barton, E., Dubert, J., Oliveira, P.B., Peliz, A., da Silva, J., 2007. Physical oceanography of the western iberia ecosystem: latest views and challenges. Prog. Ocean $74,149-173$.

Roughan, M., Terrill, E.J., Largier, J.L., Otero, M.P., 2005a. Observations of divergence and upwelling around Point Loma California. J. Geophys. Res. 110, C04011.

Roughan, M., Mace, A., Largier, J., Morgan, S., Fisher, J., 2005b. Sub-surface recirculation and larval retention in the lee of a small headland: a variation on the upwelling shadow theme. J. Geophys. Res. 110, C10027.

Sanay, R., Yankovsky, A., Voulgaris, G., 2008. Inner shelf circulation patterns and nearshore flow reversal underdownwelling and stratified conditions off a curved coastline. J. Geophys. Res. 113, C08050.

Shchepetkin, A.F., McWilliams, J.C., 2005. The regional oceanic modeling system (ROMS): a split-explicit, free-surface, topography-following coordinate oceanic model. Oceangr. Model. 9, 347-404.

Soares, P.M.M., Cardoso, R.M., de Medeiros, J., Miranda, P., Belo-Pereira, M., EspáiritoSanto, F., 2012. WRF high resolution dynamical downscaling of ERA-Interim for Portugal. Clim. Dyn. 39, 2497-2522.

Tilburg, C., 2003. Across-shelf transport on a continental shelf: do across-shelf windsmatter? J. Phys. Oceanogr. 33, 2675-2688.

Trindade, A., Peliz, A., Dias, J., Lamas, L., Oliveira, P.B., Cruz, T., 2016. cross-shelf transport in a daily varying upwelling regime: a case study of barnacle larvae on the southwestern Iberian coast. Cont. Shelf Res. 127, 12-27.

Woodson, C.B., Eerkes-Medrano, D.I., Flores-Morales, A., Foley, M.M., Henkel, S.K., Hessing-Lewis, M., Jacinto, D., Needles, L., Nishizaki, M.T., OLeary, J., Ostrander, C.E., Pespeni, M., Schwager, K.B., Tyburczy, J.A., Weersing, K.A., Kirincich, A.R., Barth, J.A., McManus, M.A., Washburn, L., 2007. Local diurnal upwelling driven by sea breeze in northern Monterey Bay. Cont. Shelf Res. 27, 2289-2302.

Zhang, Xiaoqian, Smith, X.D.C., IV, DiMarco, S.F., Hetland, R.D., 2010. A numerical study of sea-breeze-driven ocean poincare wave propagation and mixing near the critical. J. Phys. Oceanogr. 40, 48-66. 